\title{
Synthesis and characterization of metal ion-imprinted polymers
}

\author{
YASEMIN IŞIKVER* and SABRI BAYLAV \\ Hydrogel Research Laboratory, Department of Chemistry, Cumhuriyet University, 58140 Sivas, Turkey \\ *Author for correspondence (caldiran@ cumhuriyet.edu.tr)
}

MS received 2 November 2016; accepted 27 December 2017; published online 29 March 2018

\begin{abstract}
In this study, ion-imprinted polymeric materials from an aqueous solution were prepared to remove metal ions $\left(\mathrm{M}^{2+}\right)$ like $\mathrm{Ni}^{2+}, \mathrm{Co}^{2+}$, etc. To prepare ion-imprinted polymers (IIPs), acrylic acid derivatives (XA) like acrylamide (AAm), methacrylic acid and itaconic acid were chosen as monomers. Metal ions formed binary chelate complexes with the help of 8-hydroxyquinoline (8-HQ). The solution containing functional monomers and the binary complex were polymerized with the help of various cross-linkers [ethylene glycol dimethylacrylate (EGDMA) or trimethylpropane trimethacrylate (TMPTMA)] and the target ion was removed from this polymer through an applicable method to produce IIPs. Furthermore, the control polymers (CPs) were synthesized through the same method without using metal ion. Characterization of the polymeric materials was investigated through spectroscopic (FTIR/ATR), thermal (TGA, DSC) and surface (SEM and XRD) analyses. Functional monomers, cross-linkers and the target ion's species were changed during preparation of IIPs to observe their effect on imprinting of the target ion. Adsorption of the target ion to the prepared IIPs and the factors affecting the adsorption like concentration, $\mathrm{pH}$, temperature, mass, etc. were studied.
\end{abstract}

Keywords. Ion-imprinted polymers; acrylamide; acrylic acid derivatives; heavy metal ions; 8-hydroxyquinoline.

\section{Introduction}

Heavy metals affecting with toxic effects on each life stage of organisms has become a threat to nature and survival especially because of heavy metals excessive usage in industrial practices. Therefore, heavy metals must be removed from environments and environmental waters.

Different methods were developed to remove heavy metals from industrial wastewater. These include chemical methods like sedimentation, evaporation, ion exchange, electrolysis, reverse osmosis, adsorption, etc.

Polymers are materials that are light and inexpensive, have mostly sufficient mechanical features, allow easy shaping, usable for different objectives, decorative, chemically inert and resistant to corrosion. Due to such superior features, polymers are materials that attract interest not only from chemists, but also from those engaged in areas like machinerychemistry, textile, industry and physical engineering. Further, polymers have great significance in medicine, biochemistry, biophysics and molecular biology.

In recent years, molecule-imprinted polymers (MIPs) have become the focus of interest due to their many advantages. These advantages include predetermined imprinting feature, toughness, easiness, low preparation cost and potential applicability to many target molecules.

Sheykhaghaei et al [1] investigated core-shell magnetic molecularly imprinted polymer nanoparticles (MMIP-NPs) for selective extraction of tizanidine. Measurement of tizanidine obtained from MMIP-NPs showed that significant differences exist in the absorption of tizanidine and paracetamol extracted from MMIP-NPs. The imprinted polymer showed good selectivity for tizanidine [1]. Mukherjee et al [2] have examined soft solid polymer films and surfaces like cross-linked polydimethylsiloxane (PDMS)- and polyacrylamide (PAA)-based hydrogels, thermoplastics like polystyrene (PS), polymethylmethacrylate (PMMA), etc. both on planar and curved surfaces. They said that the technique can be particularly useful for the bulk nanoapplications requiring routine fabrication of templates, for example, in the study of confined chemistry phenomena, nanofluidics, bio-MEMS, micro-imprinting, optical coatings and controlled dewetting [2]. Gupta et al [3] have synthesized polyaniline (PANIs) doped with different dopants ((copper chloride $\left(\mathrm{CuCl}_{2}\right)$ and cobalt chloride $\left.\left(\mathrm{CoCl}_{2}\right)\right)$ and characterized them with scanning electron microscopy (SEM), $\mathrm{X}$-ray diffraction (XRD), Fourier transform infrared (FTIR) spectroscopy, thermogravimetric analysis (TGA), differential scanning calorimetry (DSC) and UV-visible (UV-VIS) spectroscopy. Greater thermal stability and crystallinity were observed in doped PANI vs. pure PANI. Magnetic measurements showed that the magnetic susceptibility was fielddependent. Positive- and negative-susceptibility values were observed [3]. Zhao et al [4] prepared Zn (II) IIP materials by the copolymerization of 8-acryloyloxyquinoline (8-AOQ) 
and ethylene glycol dimethacrylate (EGDMA). After removing Zn (II) ion from the polymer, MIPs capable of selectively rebinding $\mathrm{Zn}$ (II) ion were obtained. The maximum adsorption capacity of $\mathrm{Zn}$ (II) on MIPs beads determined about $3.9 \mathrm{mg} \mathrm{g}^{-1}$ [4]. Singh et al [5] prepared the IIPs by copolymerization of 2-hydroxyethyl methacrylate with nickel vinyl benzoate complex in the presence of ethylene glycol dimethacrylate. The synthesized polymers were characterized by surface area measurements, FTIR, microanalysis and SEM analysis. The adsorption capacity of IIPs and control polymers (CPs) was found to be 1.51 and $0.65 \mathrm{mmol} \mathrm{g}^{-1}$, respectively [5]. Saraji et al [6] synthesized SPE material for selective preconcentration of $\mathrm{Ni}$ ions from water samples. The imprinted polymer had obvious imprinting effect on the imprinting ion. The values of the relative selectivity factor were found to be 21.6, 54.3 and 22.7 for $\mathrm{Co}(\mathrm{II}), \mathrm{Cu}$ (II) and $\mathrm{Cd}$ (II), respectively. The proposed procedure was applied for the determination of $\mathrm{Ni}$ in river- and wastewater samples [6].

IIPs are closely similar to MIPs. Herein, metal ions are used as the target molecule and have all features of all MIPs.

\section{Experimental}

\subsection{Chemicals}

Acrylamide (AAm) (Merck, Darmstadt, Germany), methacrylic acid (MA) (Merck, Darmstadt, Germany) and itaconic acid (IA) (Sigma, St. Louis, USA) as monomers, ethylene glycol dimethacrylate (EGDMA) (Merck, Schuchardt, Germany), trimethylolpropane trimethacrylate (TMPTMA) (Sigma, St. Louis, USA) as cross-linkers, azobisisobutyronitrile (AIBN) (Fluka Chemie AG CH-9470 Buchs) as initiator were analytical grade and were used as received. $\mathrm{NiCl}_{2} \cdot 6 \mathrm{H}_{2} \mathrm{O}$, $\mathrm{CoCl}_{2} \cdot 6 \mathrm{H}_{2} \mathrm{O}$ and 8-hydroxyquinoline (HQ) were obtained from Merck Chemicals.

\subsection{Preparation of IIPs}

To prepare IIPs, acrylic acid derivatives (XA) like acrylamide (AAm), methacrylic acid and itaconic acid were chosen as monomers. The solutions containing functional monomers and the binary metal ion-8-hydroxyquinoline complex were polymerized with the help of various cross-linkers (ethylene glycol dimethylacrylate (EGDMA) or trimethylpropane trimethacrylate (TMPTMA)) through the radical addition reaction in solution and the target ion was removed from this polymer through an applicable method to IIPs. Further, the CPs were synthesized through the same method without using metal ion. Amount of matter used in the preparation of polymers and illustrations of the synthesized polymers are seen in table 1 .

First, the target metal ion $\left(\mathrm{Ni}^{2+}\right.$ or $\left.\mathrm{Co}^{2+}\right)$ and $\mathrm{HQ}$ were stirred in methanol-toluene (3:1) mixture for $2 \mathrm{~h}$. Then, AAm, MA or IA monomers and the cross-linker (EGDMA or TMPTMA) were added to this mixture and stirred for $3 \mathrm{~h}$

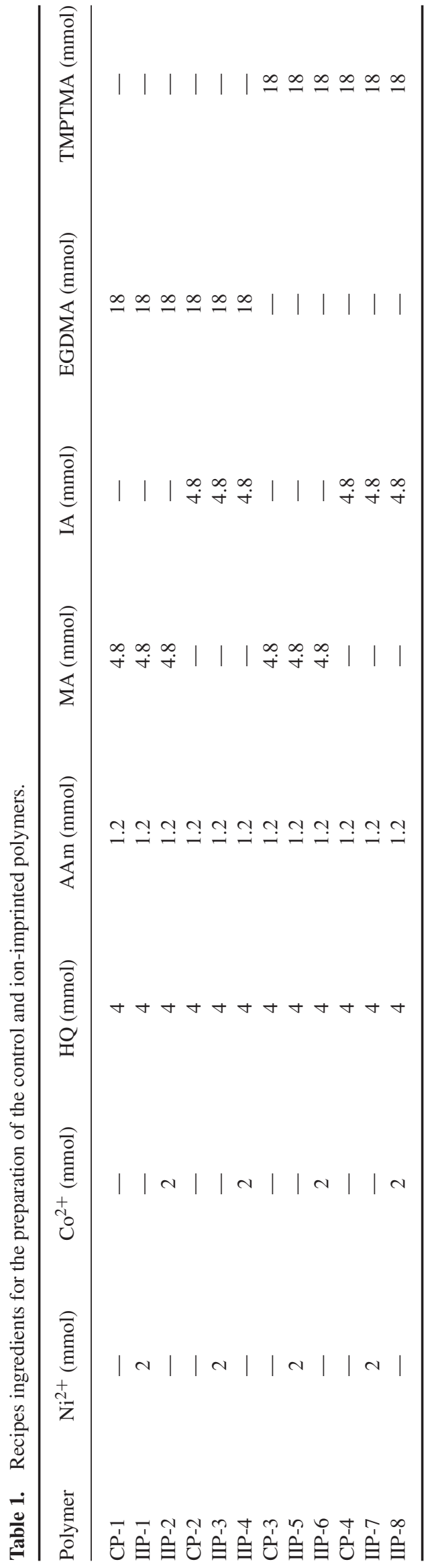


at room temperature. AIBN was added to the solution as initiator and then, $\mathrm{N}_{2}$ gas was made to pass through the solution for $10 \mathrm{~min}$ and polymerization took place at $60^{\circ} \mathrm{C}$ (IIP). The CPs (non-imprinted polymers) were synthesized through the same method under the same conditions without using metal ion (CP). All the prepared polymers were leached with methanol and dried.

The polymers, which were synthesized to remove metal ions from the imprinted polymers, were leached four times with $250 \mathrm{ml}$ of $0.1 \mathrm{M} \mathrm{HNO}_{3}$ for $24 \mathrm{~h}$ at room temperature and washed with $250 \mathrm{ml}$ of distilled water twice for $24 \mathrm{~h}$. Then, they were dried. The indications of IIP-1, IIP-3, IIP-5, IIP-7 were used for nickel-imprinted IPPs, while the indications of IIP-2, IIP-4, IIP-6, IIP-8 were used for cobalt-imprinted IIPs.

As number of synthesized polymers is high, IIPs and CPs that were cross-linked with EGDMA were selected for characterization of the polymers.

\subsection{Characterization}

For the characterization of the prepared polymeric materials, spectroscopic (FTIR/ATR), thermal (TGA, DSC) and surface (SEM and XRD) analyses were conducted.

FTIR spectra of the polymers were recorded with FTIR/ATR Perkin Elmer 100 Pike Gladi spectrofotometer in the $4000-400 \mathrm{~cm}^{-1}$ range and 30 scans were taken at $4 \mathrm{~cm}^{-1}$ resolution.

TGA was carried out using TG and DSC (Shimadzu50 model thermal analyzer). TGA analyses were performed employing $10 \mathrm{mg}$ samples in a platinum pan heating up to $600^{\circ} \mathrm{C}$ under nitrogen gas flow rate of $25 \mathrm{ml} \mathrm{min}^{-1}$ with a heating rate of $10^{\circ} \mathrm{C} \mathrm{min}^{-1}$.

SEM (Leo EVO 40XVP) was used to investigate surface morphology of the prepared polymers.

The materials' phase imprinting and crystal structure were conducted in the scanning ratio of $30 \mathrm{~min}^{-1}$ within $30^{\circ}$ and $80^{\circ} 2 \theta$, by using $(\lambda=15,405 \AA) \mathrm{Cu} \alpha$ through Rigaku RadBDMAX II model X-ray diffractometer. In the experimental system, the analyses were conducted according to the powder diffraction method and X-ray diffractograms of the relevant polymers were taken.

\subsection{Metal ion adsorption in IIPs}

The target ion's adsorption to the prepared polymers was investigated and the factors affecting the adsorption like concentration, $\mathrm{pH}$, temperature, mass, etc. were studied.

The effect of $\mathrm{pH}$, temperature and the adsorbent mass on the adsorption was examined in the metal ions solution of $50 \mathrm{mg}^{-1}$ at $25^{\circ} \mathrm{C}$.

To investigate the effect of metal ion concentration on adsorption, $0.1 \mathrm{~g}$ of dry polymer was buffered with acetate buffer to $\mathrm{pH}=7.0$ and brought to the equilibrium and placed in $50 \mathrm{ml}$ of aqueous metal ion solution at the concentration of 5-100 $\mathrm{mg} \mathrm{l}^{-1}$ at $25^{\circ} \mathrm{C}$ for $24 \mathrm{~h}$.
The ability of the IIPs to use for several times was investigated through adsorption-desorption studies. The matter adsorbed from the metal ion solution with a concentration of $50 \mathrm{mg} \mathrm{l}^{-1}$ that was buffered with acetate buffer to $\mathrm{pH}=$ 7.0 at $25^{\circ} \mathrm{C}$ was determined. Then, the polymers filtered from these solutions were leached with $\mathrm{HNO}_{3}$ and water and metal ion desorption was ensured. This process was repeated four times.

All spectrophotometric measurements of these metal ion solutions were carried out using a Shimadzu FAAS 6300 model flame atomic absorption spectrophotometer.

\section{Results and discussion}

\subsection{Preparation of IIPs}

The IIPs were produced by mixing the monomers and crosslinker with the metal ion-chelate complex to give radical addition reaction in solution with AIBN $[7,8]$.

Model of $\mathrm{Ni}^{2+}$ ion-imprinted $\mathrm{P}(\mathrm{AAm}-\mathrm{co}-\mathrm{MA})$ polymers is seen in scheme 1 [9].

To remove metal ions, IIPs were leached with $\mathrm{HNO}_{3}$ four times and with distilled water twice. Metal ion concentration in the leaching solutions were determined and plotted $v s$. number of leachings to be given, in figure 1 .

As seen in figure 1, almost all metal ions in the IIPs were removed after the first leaching with $\mathrm{HNO}_{3}$. No metal ion was left in IIPs after third leaching.

\subsection{Characterization}

Spectroscopic, thermal and surface analyses were conducted on the CPs and IIPs that were cross-linked with EGDMA.

3.2a FTIR analysis: Typical spectra of the control, unleached and leached polymers are shown in figure 2 .

In all metal ion imprinted polymers, a $\mathrm{C}-\mathrm{H}$ strong alkane (aliphatic) stretching band at wavenumber of $2956 \mathrm{~cm}^{-1}$ was observed. This emphasizes that $\mathrm{C}-\mathrm{H}$ group intensively exists in the group polymers at this wavenumber.

In addition, in all the polymers, a strong carbonyl $\mathrm{C}=\mathrm{O}$ stretching band at the wavenumber of $1722 \mathrm{~cm}^{-1}, \mathrm{C}=\mathrm{C}$ variable alkene stretching band at $1636 \mathrm{~cm}^{-1}$ and $\mathrm{N}-\mathrm{H}$ strong amide stretching band at $1450 \mathrm{~cm}^{-1}$ were observed.

Due to the monomers in the polymeric structure containing - $\mathrm{COOH}$ groups, $\mathrm{C}-\mathrm{O}$ strong stretching band was observed at the wavenumber of $1150 \mathrm{~cm}^{-1}$.

IR spectra of the leached IIPs and CPs are very similar to each other. Thus, it may be said that leaching process does not harm the polymer network, while it removes the target species.

3.2b TGA: The thermal degradation values of the polymers were found in the thermograms (figure 3).

According to the TG thermograms, CPs and the leached IIP polymers give one-step thermal decomposition reaction, 

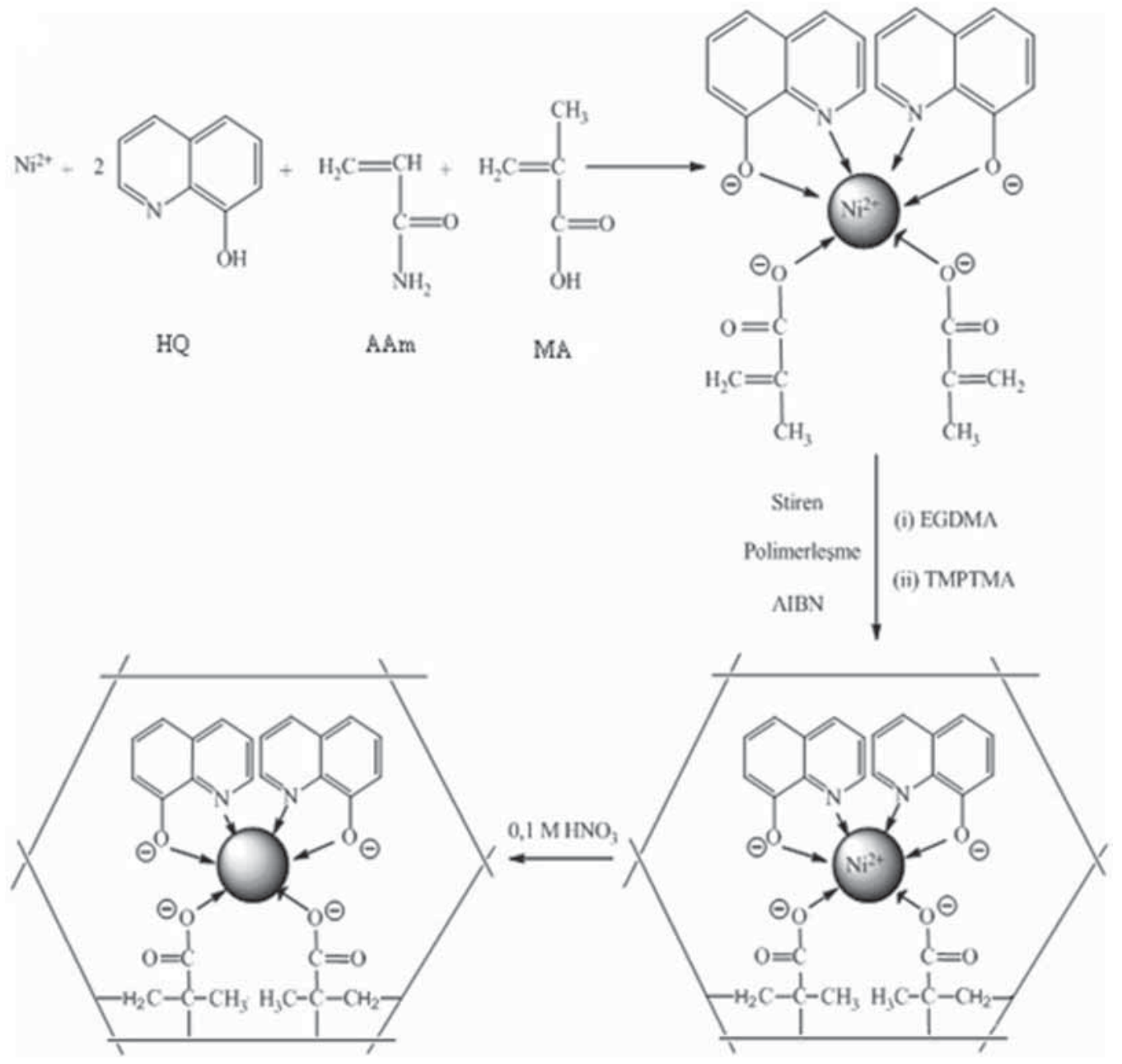

Scheme 1. Preparation of $\mathrm{Ni}^{2+}$ ion-imprinted $\mathrm{P}(\mathrm{AAm}-\mathrm{co}-\mathrm{MA})$ polymers.

while unleached IIP polymers give two-step thermal decomposition reaction. In all polymers, mass loss until $\sim 100^{\circ} \mathrm{C}$ was resulted from evaporation of the solvent bounded in the structure of the polymer. It is seen that any structural decomposition due to heat did not occur in CPs and leached IIP polymers until $250^{\circ} \mathrm{C}$. On the other hand, initial decomposition temperature is around $120-130^{\circ} \mathrm{C}$ for unleached IIP polymers and the reason is the metal-HQ complex [8]. It is seen that no thermal decomposition takes place until $150^{\circ} \mathrm{C}$ in unleached IIP polymer. Decomposition of carboxyl groups occurs in the interval of $250-400^{\circ} \mathrm{C}$ as a result of intramolecular and intermolecular reactions. It was reported that carboxyl groups leave the structure at temperature above $200^{\circ} \mathrm{C}$ and its significance increases at temperature above $250^{\circ} \mathrm{C}$ [10]. Molar decomposition occurs at temperature above $400^{\circ} \mathrm{C}$ including main chain break of the remaining polymer.

The initial degradation temperature $\left(T_{\mathrm{i}}\right)$, the temperature of maximum speed $\left(T_{\max }\right)$, the degradation final temperature $\left(T_{\mathrm{f}}\right)$, the half-life temperature $\left(T_{\mathrm{h}}\right)$, the maximum decomposition rate $\left(r_{\max }\right)$ and the maximum speed of the substance $\left(C_{\max }\right)$ values are given table 2 .
CP-1 polymer's all temperature values were found to be quite close to those of leached and unleached IIP-1 and IIP-2 polymers. This is almost applicable to CP-2 and leached IIP-3 and IIP-4 polymers. This shows that IIP polymers' metal ions are removed quite efficiently by leaching. Furthermore, unleached IIP polymers' all temperature values are higher than those of the leached polymers due to their metal ion content. Remaining matter values at maximum speed $\left(C_{\max } \%\right)$ vary between 39 and $69 \%$.

3.2c DSC analysis: DSC thermograms of the control, unleached and leached polymers are given in figure 4 .

Glass transition temperature of the polymers determined with the DSC thermograms and the results are given in table 3.

$T_{\mathrm{g}}$ values of the polymers, which were prepared by using methacylic acid containing one carboxyl group were found higher than $T_{\mathrm{g}}$ values of the polymers, which were prepared by using itaconic acid containing two carboxyl groups. It is seen that $T_{\mathrm{g}}$ values of the IIPs prepared by using itaconic acid decrease due to plasticizing effect of $-\mathrm{COOH}$ groups in the polymers. Furthermore, $T_{\mathrm{g}}$ values of unleached IIPs are lower 


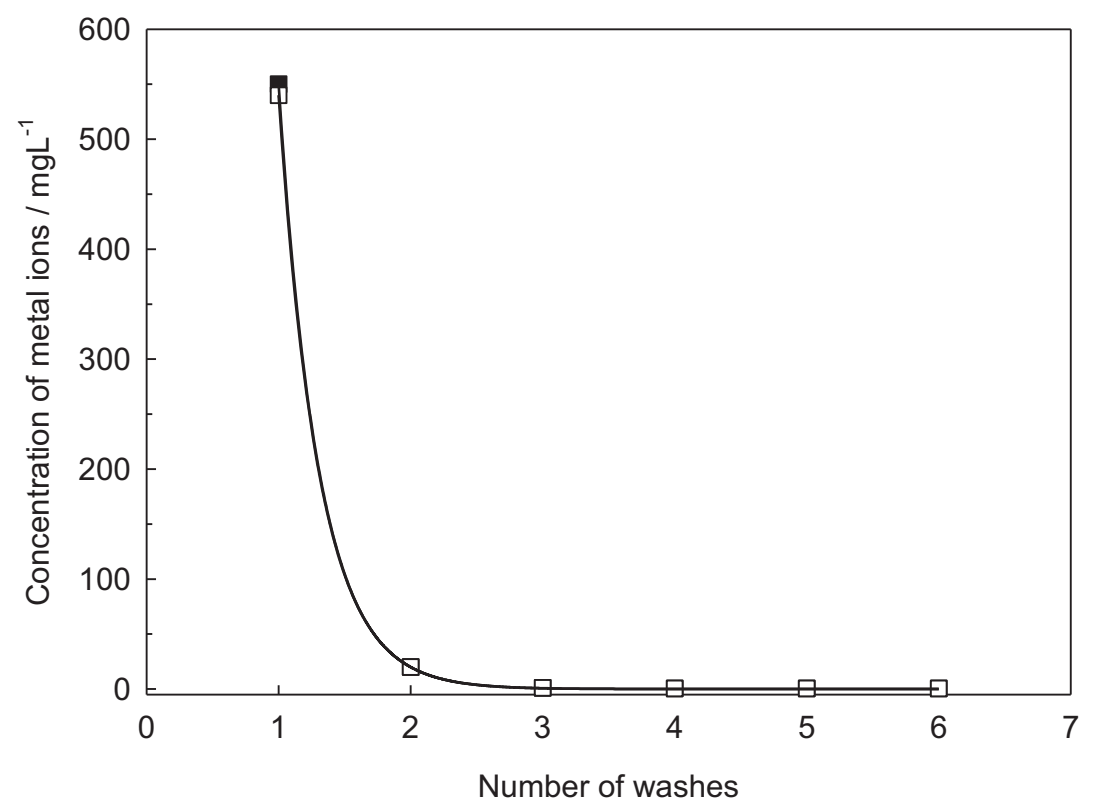

Figure 1. Concentration of metal ions which was removed after washing. a, IIP-1; $\square$, IIP-2.

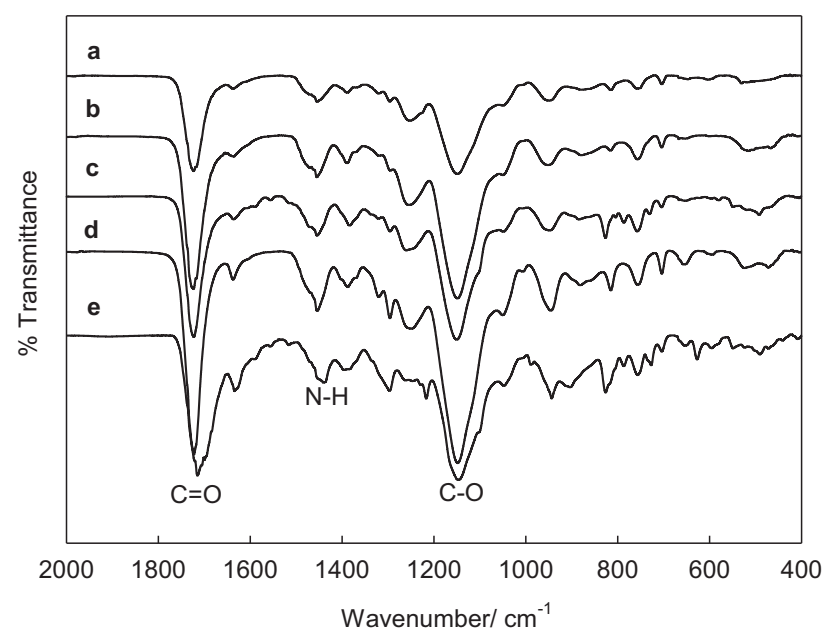

Figure 2. FTIR spectra of the control, unleached and leached ionimprinted polymers: (a) CP-1, (b) leached IIP-1, (c) unleached IIP-1, (d) leached IIP-2 and (e) unleached IIP-2.

than those of leached polymers due to plasticizing effect of metal ions. The polymers maintain their hard and vitreous nature until at $\sim 70^{\circ} \mathrm{C}$.

3.2d SEM analysis: Figure 5 shows SEM images of the prepared polymers at $1 \mu \mathrm{m}$ in $20.00 \mathrm{KX}$ magnifying values.

Quite regular and uniform characteristic surface structure was observed in SEM images of the polymers. There are local gaps on the polymers' surfaces and they are distributed uniformly.

According to the polymers' SEM images, the metal IIPs cause a visual change in the matrix, while SEM images of the CP and leached IIPs are similar to each other. Small morphological differences between them are resulted from the presence of the target ion in polymerization. As a result, an intermediate material that is close to nonimprinted polymers is produced by removing metal ions by leaching.

A significant difference is seen between the scanning electron micrographs of unleached IIPs and CPs. SEM images of the unleached IIPs show more than the target ion, which is bound uniformly. A rough and aggregated structure was observed on surface of unleached IIPs due to the metal ions that are bounded [5,9].

There are many micropores on surface of leached IIPs allowing the target ion to bind easily because the leached IIPs are products of cross-linking and imprinting reactions are increasing the adsorption surface area and producing open places on the surface allowing binding.

3.2e XRD analysis: XRD patterns of the polymers and imprinted metal salts were taken and presented in figure 6.

The polymers' XRD patterns were characterized by angular position ( $2 \theta$ /scattering angle). In $\mathrm{NiCl}_{2} \cdot 6 \mathrm{H}_{2} \mathrm{O}$ salt's XRD pattern, the values of $2 \theta=16.5,18.6,29.2,32.8,35.5,37.5$ are diffraction peaks [11]. These peaks are available in unleached polymer too; however, it is not significant due to amorphous 

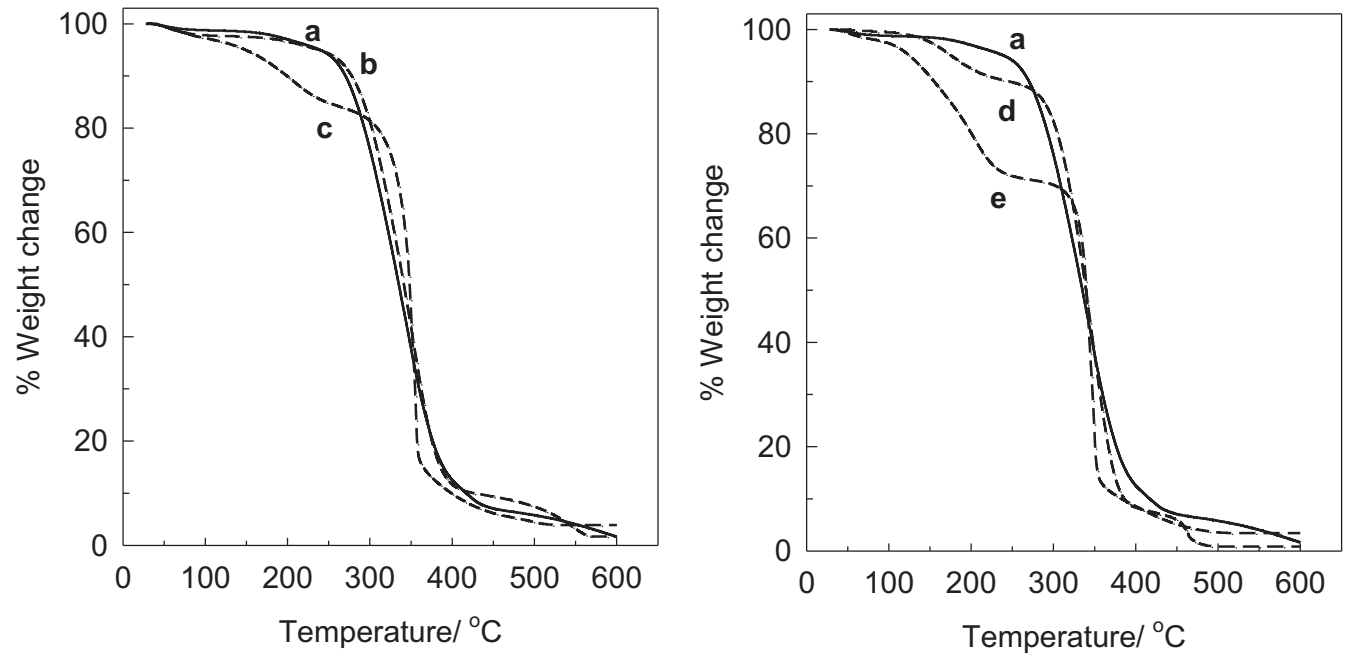

Figure 3. TGA thermograms of the control, unleached and leached ion-imprinted polymers: (a) CP-1, (b) leached IIP-1, (c) unleached IIP-1, (d) leached IIP-2 and (e) unleached IIP-2.

Table 2. Thermodynamic properties of the control, unleached and leached ion-imprinted polymers.

\begin{tabular}{|c|c|c|c|c|c|c|c|c|}
\hline Polymer & $T_{\mathrm{i}(1)}\left({ }^{\circ} \mathrm{C}\right)$ & $T_{\mathrm{i}(2)}\left({ }^{\circ} \mathrm{C}\right)$ & $T_{\max }\left({ }^{\circ} \mathrm{C}\right)$ & $T_{\mathrm{f}(1)}\left({ }^{\circ} \mathrm{C}\right)$ & $T_{\mathrm{f}(2)}\left({ }^{\circ} \mathrm{C}\right)$ & $T_{\mathrm{h}}\left({ }^{\circ} \mathrm{C}\right)$ & $r_{\max }\left(\mathrm{mg} \mathrm{dk}^{-1}\right)$ & $C_{\max }(\%)$ \\
\hline $\mathrm{CP}-1$ & - & 269.6 & 344.1 & - & 383.6 & 334.9 & 0.93 & 43.70 \\
\hline $\mathrm{CP}-2$ & - & 254.4 & 293.2 & - & 382.4 & 322.8 & 0.73 & 67.96 \\
\hline Unleached IIP-1 & 131.5 & 338.3 & 352.4 & 247.4 & 358.5 & 348.0 & 4.09 & 41.11 \\
\hline Leached IIP-1 & - & 275.7 & 354.0 & - & 382.1 & 341.8 & 1.00 & 39.23 \\
\hline Unleached IIP-2 & 119.8 & 332.8 & 345.6 & 233.0 & 352.6 & 340.5 & 4.14 & 61.84 \\
\hline Leached IIP-2 & - & 295.1 & 347.8 & - & 377.2 & 339.9 & 0.84 & 40.47 \\
\hline Unleached IIP-3 & 121.1 & 336.5 & 356.3 & 199.5 & 364.4 & 344.7 & 2.65 & 53.56 \\
\hline Leached IIP-3 & - & 264.6 & 292.6 & - & 382.5 & 314.3 & 0.90 & 68.89 \\
\hline Unleached IIP-4 & 119.2 & 331.0 & 349.0 & 228.1 & 366.8 & 330.4 & 1.20 & 48.66 \\
\hline Leached IIP-4 & - & 310.2 & 336.6 & - & 373.6 & 337.2 & 1.88 & 50.32 \\
\hline
\end{tabular}

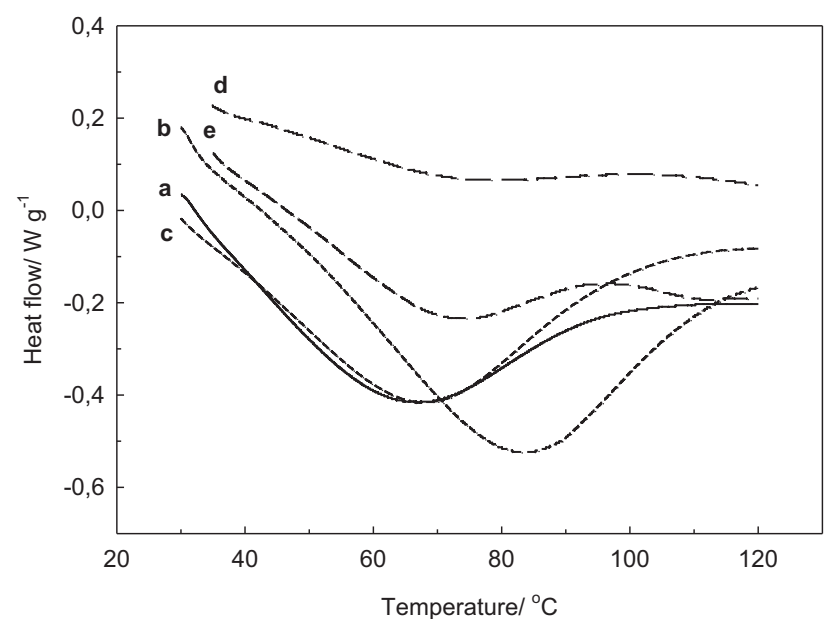

Figure 4. DSC thermograms of the control, unleached and leached ion-imprinted polymers: (a) CP-1, (b) leached IIP-1, (c) unleached IIP-1, (d) leached IIP-2 and (e) unleached IIP-2.
Table 3. Glass transition temperature of the control, unleached and leached ion-imprinted polymers.

\begin{tabular}{lc}
\hline Polymer & $T_{\mathrm{g}}\left({ }^{\circ} \mathrm{C}\right)$ \\
\hline CP-1 & 64.81 \\
CP-2 & 59.43 \\
Unleached IIP-1 & 66.15 \\
Leached IIP-1 & 78.53 \\
Unleached IIP-2 & 70.61 \\
Leached IIP-2 & 73.25 \\
Unleached IIP-3 & 54.07 \\
Leached IIP-3 & 67.89 \\
Unleached IIP-4 & 66.04 \\
Leached IIP-4 & 69.35 \\
\hline
\end{tabular}



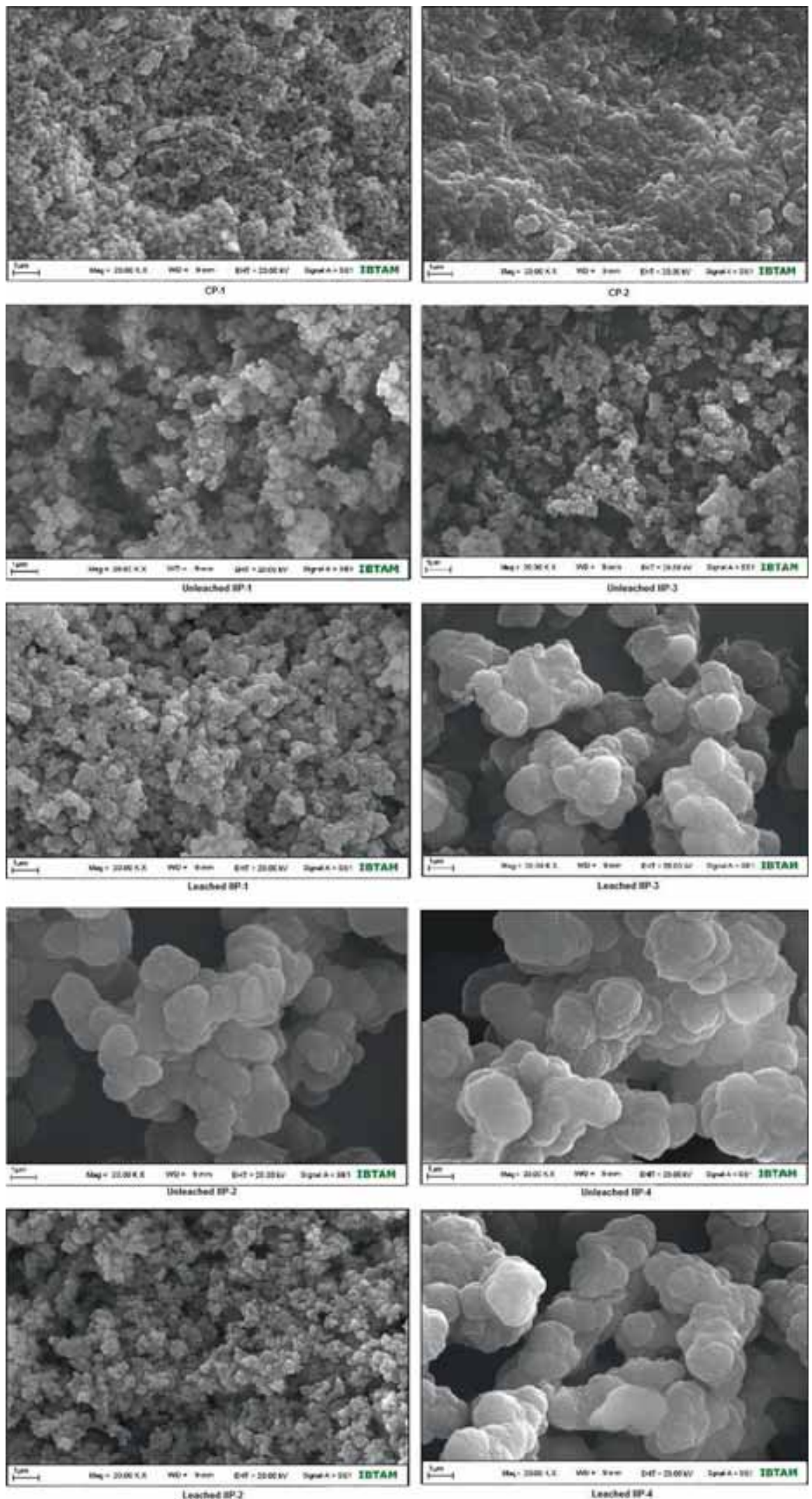

Figure 5. SEM pictures of the control, unleached and leached ion-imprinted polymers $(20.00$ $\mathrm{KX}-1 \mu \mathrm{m})$. 


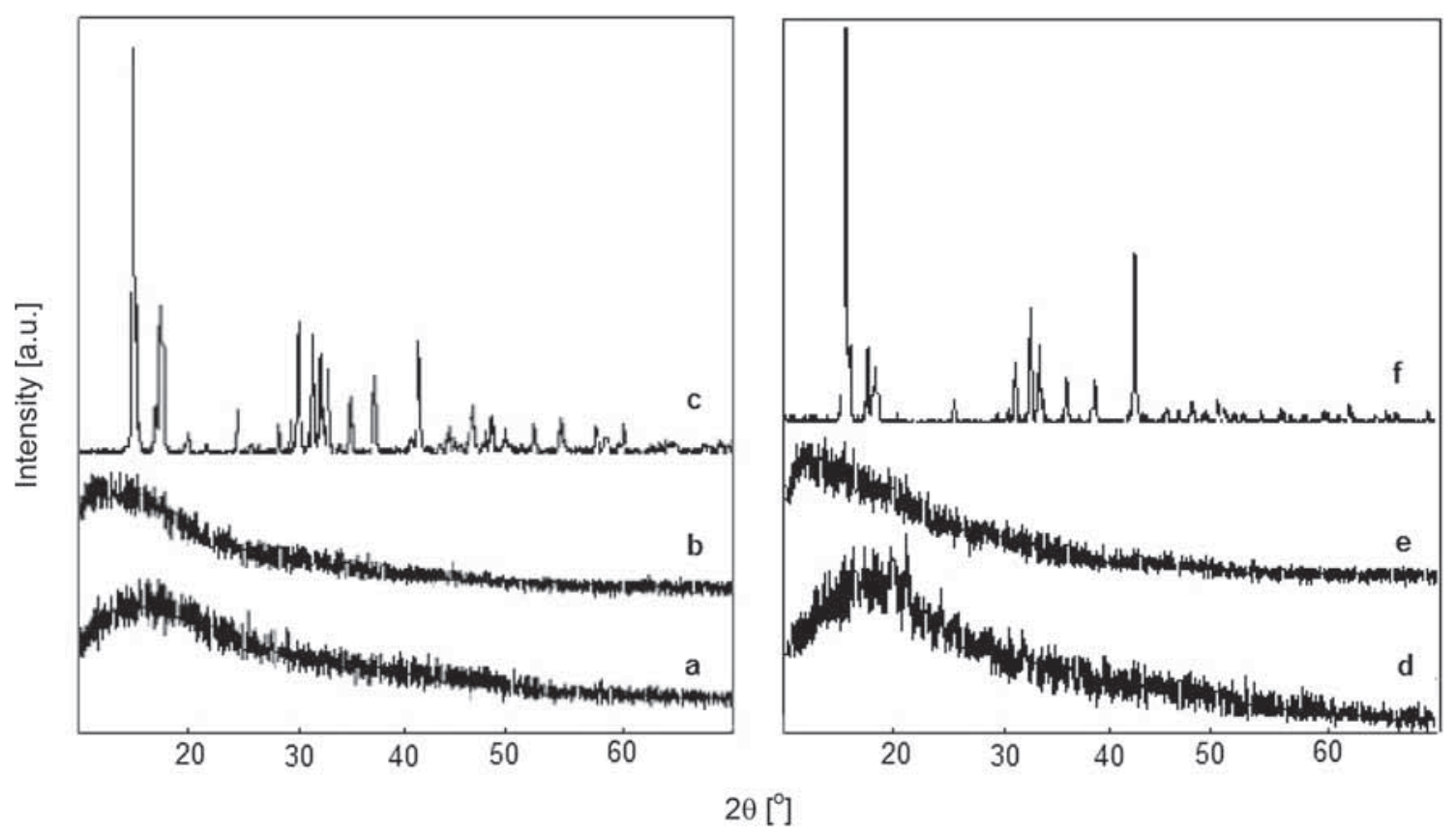

Figure 6. XRD patterns of the polymers: (a) unleached IIP-1, (b) leached IIP-1, (c) $\mathrm{NiCl}_{2} \cdot 6 \mathrm{H}_{2} \mathrm{O}$, (d) unleached IIP-2, (e) leached IIP-2 and (f) $\mathrm{CoCl}_{2} \cdot 6 \mathrm{H}_{2} \mathrm{O}$.
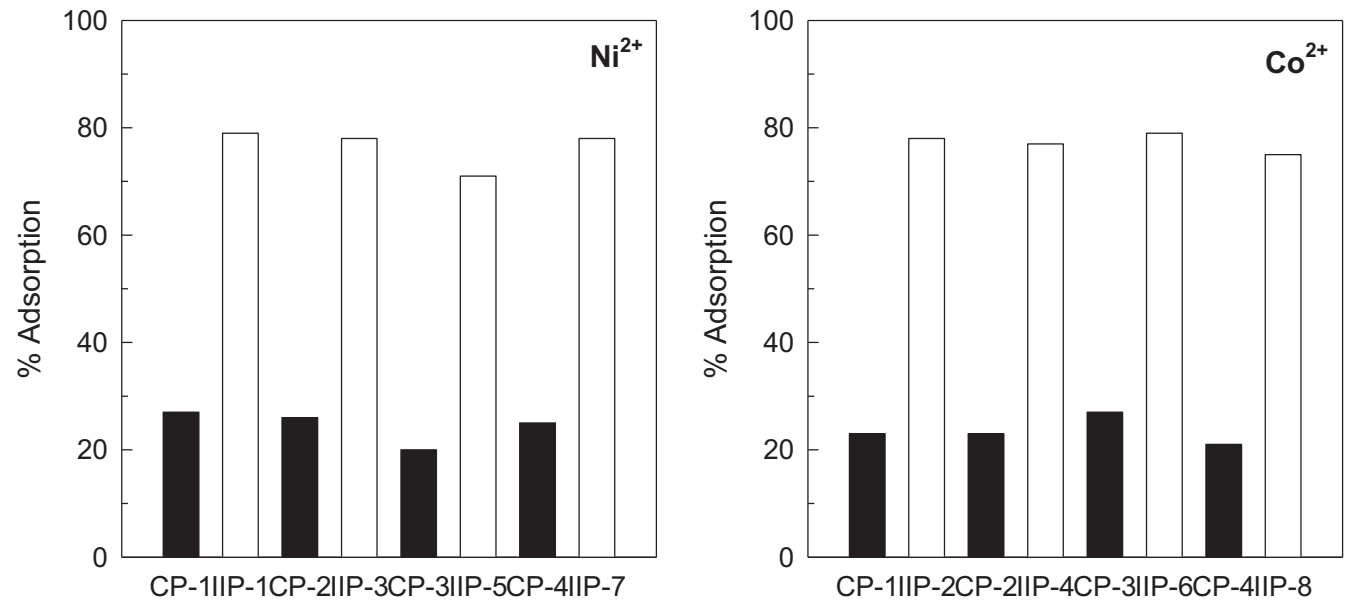

Type of the materials

Figure 7. The adsorbed matter amounts by the polymers.

nature of the polymer. On the other hand, it is seen that these peaks are lost in leached IIPs. This shows that all nickel ions are removed from the polymer by leaching. Similar explanations may be made for $\mathrm{Co}^{2+}$ IIPs.

\subsection{Metal ion adsorption in IIPs}

The effective $\mathrm{pH}$, temperature, adsorbent mass and concentration on adsorption of metal ion to the polymers were investigated.
In a batch adsorption system at equilibrium, total cosolute concentration $\left(C_{\mathrm{I}}, \mathrm{mol} \mathrm{l}^{-1}\right)$ is

$$
C_{\mathrm{I}}=C_{\mathrm{B}}+C
$$

where $C_{\mathrm{B}}$ is the equilibrium concentration of the cosolute on the adsorbent in moles per litre (bound cosolute concentration), and $C$ the equilibrium concentration of the cosolute in the solution in $\mathrm{mol}^{-1}$ (free cosolute concentration) [12]. The amount of metal ion adsorbed onto the polymers at equilibrium concentration, $q$, at a given temperature and $\mathrm{pH}$ is 
calculated from the equation:

$$
q=\frac{C_{\mathrm{B}} V}{m},
$$

where $V$ is the volume of solution (l) and $m$ is the mass of polymers (g).

Adsorption percentage (adsorption\%) is calculated by the following equation:

$$
\text { Adsorption } \%=\frac{C_{\mathrm{B}}}{C} \times 100 \text {. }
$$

The matter adsorbed by each control and IIP at $25^{\circ} \mathrm{C}$ from the solutions containing $500 \mathrm{mg} \mathrm{l}^{-1}$ metal ion buffered by acetate buffer until $\mathrm{pH}=7.0$ was calculated. Adsorption\% values were plotted $v s$. type of the prepared polymeric materials and are presented in figure 7.

As seen in figure 7, metal ion amount adsorbed by IIPs is 4-folds of that adsorbed by the CPs. After the target species are removed, IIP imprinting cavity zones that emerge, will show supplementary feature to the imprinted target species size and coordination geometry. However, the ligand functionality in $\mathrm{CP}$ polymer network structure shows random distribution. The fact that IIPs, which were imprinted by metal ions will have a memory feature i.e., adsorb more material than that of CPs, which do not have such feature, is an aimed and expected result.

3.3a Effect of $p H$ : To investigate the $\mathrm{pH}$ effect on metal ion adsorption, $0.1 \mathrm{~g}$ of dry polymer was buffered with acetate buffer until five different $\mathrm{pH}$ values $(3,4,5,6,7)$ at $25^{\circ} \mathrm{C}$ and placed into the metal ion solution with a concentration of $50 \mathrm{mg} \mathrm{l}^{-1}$ to be maintained for $24 \mathrm{~h}$. The adsorbed matter $(q)$ at each $\mathrm{pH}$ was calculated and the curves showing variation in the adsorbed amount $v s . \mathrm{pH}$ are presented in figure 8 .

As seen in figure 8, the metal ion amount adsorbed by the polymers varies depending on $\mathrm{pH}$ and achieves the highest point at $\mathrm{pH}=7.0$. Therefore, effects of temperature and concentration were investigated at $\mathrm{pH}=7.0$.

It is known that the polymers containing $-\mathrm{COOH}$ groups are ionized when $\mathrm{pH}$ increases and thus, they have more interactions with metal ions. Furthermore, when $\mathrm{pH}$ increases, metal ion-HQ complex formation trend increases.

3.3b Effect of temperature: To investigate the effect of temperature on metal ion adsorption, $0.1 \mathrm{~g}$ of dry polymer was buffered with acetate buffer until $\mathrm{pH}=7.0$ and placed into the metal ion solution with a concentration of $50 \mathrm{mg}^{-1}$ to be maintained for $24 \mathrm{~h}$ at five different temperatures (25, $30,35,40$ and $\left.45^{\circ} \mathrm{C}\right)$. The adsorbed matter $(q)$ at each temperature was calculated and the curves showing variation in the adsorbed amount $v s$. temperature are presented in figure 9 .

As seen in figure 9, the adsorbed material does not vary significantly within the temperature interval under study. Thus, temperature has no significant effect on the metal ion amount adsorbed by the polymers within the relevant temperature interval.

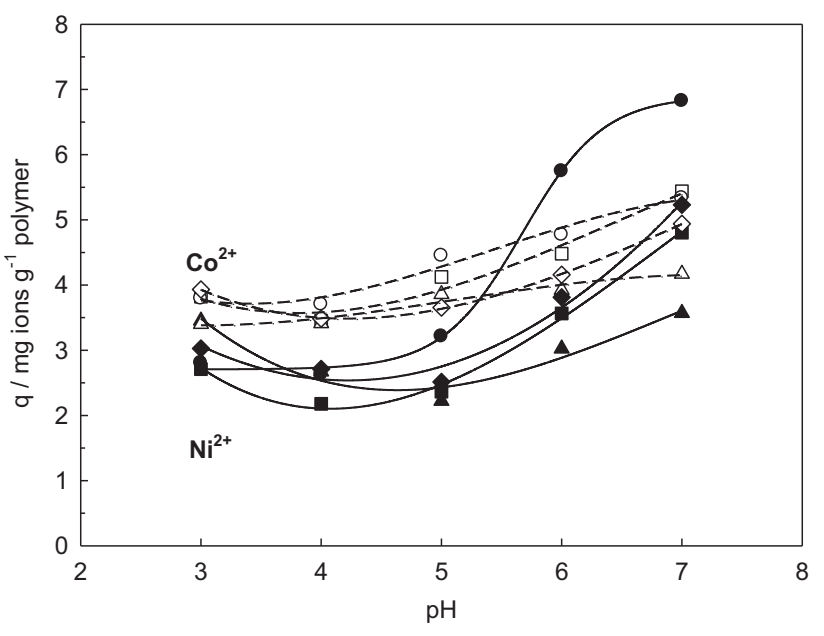

Figure 8. Effect of $\mathrm{pH}$ of metal ions adsorption onto IIP materials. घ, IIP-1; •, IIP-3; $\boldsymbol{\Delta}$, IIP-5; •, IIP-7; 口, IIP-2; o, IIP-4; $\triangle$, IIP-6; $\diamond$, IIP-8.

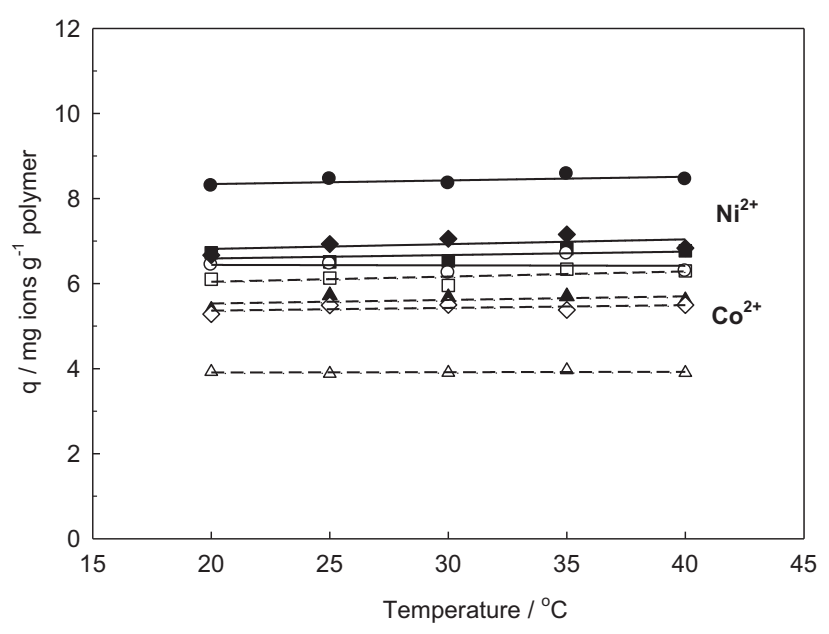

Figure 9. Effect of temperature of metal ions adsorption onto IIP

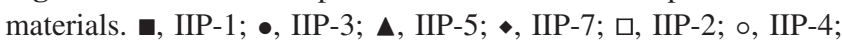
$\triangle$, IIP-6; $\diamond$ IIP-8.

3.3c Effect of adsorbent's mass: To investigate the effect of adsorbent's mass on metal ion adsorption, dry polymer in the interval of 0.02-0.1 g was buffered with acetate buffer until $\mathrm{pH}=7.00$ and placed into the metal ion solution with a concentration of $50 \mathrm{mg} \mathrm{l}^{-1}$ to be maintained for $24 \mathrm{~h}$ at $25^{\circ} \mathrm{C}$. The adsorbed matter $(q)$ at each adsorbent mass was calculated and the curves showing variation in the adsorbed amount $v s$. adsorbent mass are presented in figure 10.

As seen in figure 10, the adsorbed material increases when the adsorbent's mass increases and reaches almost equilibrium at the point of $0.1 \mathrm{~g}$.

3.3d Effect of concentration: To investigate the effect of metal ion concentration on adsorption, $0.1 \mathrm{~g}$ of dry polymer was buffered with acetate buffer until $\mathrm{pH}=7.0$ and placed 
into the $\mathrm{Ni}^{2+}$ and $\mathrm{Co}^{2+}$ solutions with concentrations of $5-100 \mathrm{mg}^{-1}$ to be maintained for $24 \mathrm{~h}$ at $25^{\circ} \mathrm{C}$. The isotherms produced for plotting the adsorbed matter $(q) v s$. the concentration at the equilibrium are seen in figure 11.

As seen in figure 11, the isotherms of the metal ion adsorption by the prepared polymers resemble L isotherms according to the Giles adsorption isotherm classification [13]. As known, L-type isotherms' most qualitative feature is the fact that the adsorbed molecules have a strong intermolecular action with the adsorbent. It was ensured that strong interactions occur between the adsorbent's type and the adsorbed by creating memory effect through the imprinting process.

Furthermore, according to the adsorption isotherms, it is seen that number of carboxyl in the carboxylic acid monomer

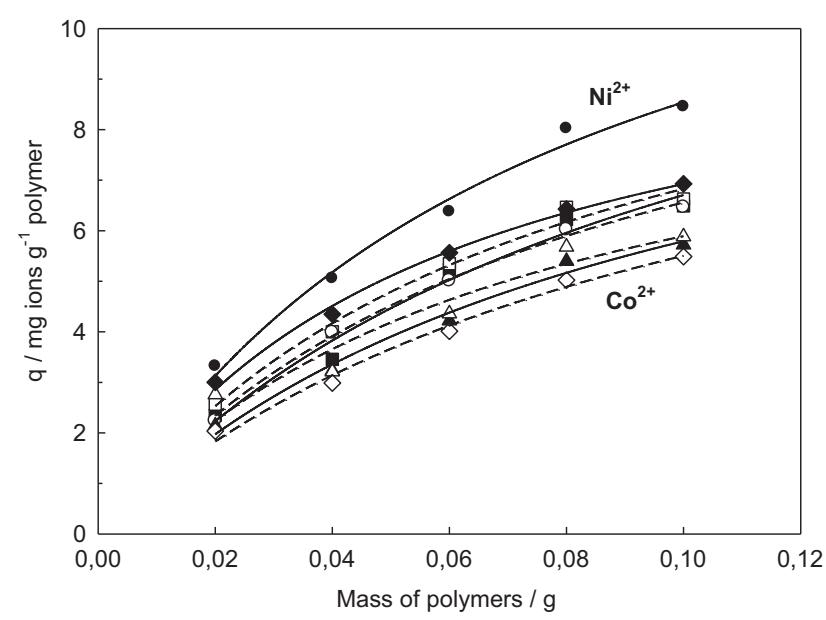

Figure 10. Effect of mass of metal ions adsorption onto IIP mate-

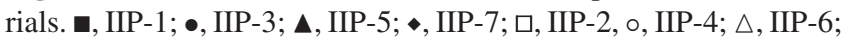
$\diamond$, IIP-8. used in the production of the polymeric material has no significant effect on adsorption.

3.3e Effect of repeatability: One hundred milligrams of dry polymer was buffered until $\mathrm{pH}=7.0$ with acetate buffer and placed into the solution containing metal ions at a concentration of $50 \mathrm{mg} \mathrm{l}^{-1}$ to be maintained for $24 \mathrm{~h}$ at $25^{\circ} \mathrm{C}$. After adsorption, equilibrium concentrations of the metal ions were determined and the adsorbed material amounts were calculated. After adsorption, metal ions bound to the polymers were leached with $0.1 \mathrm{M} \mathrm{HNO}_{3}$ and water is removed and metal ion amounts in the leaching solutions were observed via FAAS. Adsorption-desorption processes were repeated

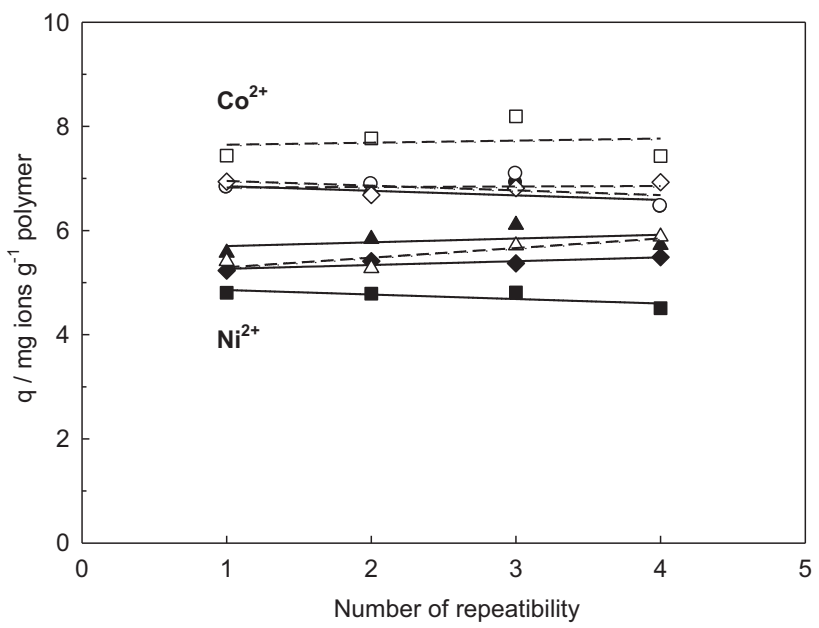

Figure 12. Repeatabilities of the prepared IIPs for metal ion

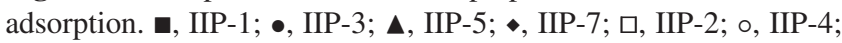
$\triangle$ IIP-6; $\diamond$ IIP-8.

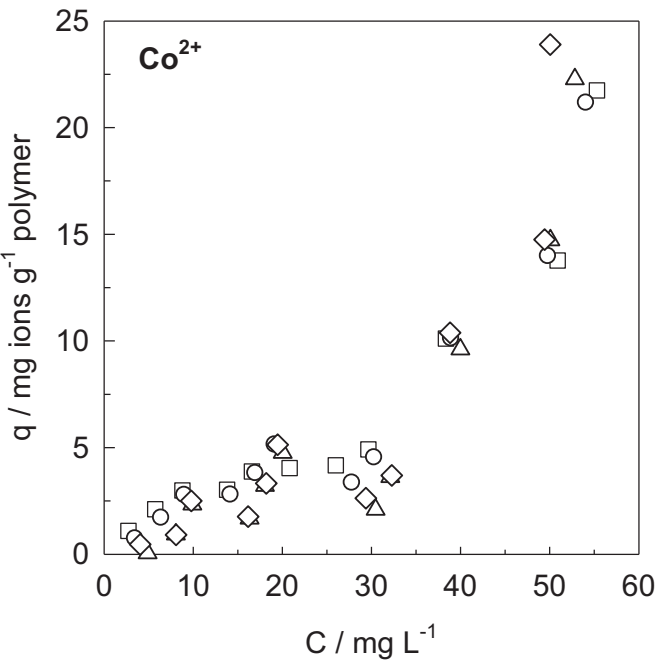

Figure 11. Effect of concentration of metal ions adsorption onto IIP materials. $\mathbf{}$, IIP-1; $\bullet$ IIP-3; $\boldsymbol{\Delta}$, IIP-5; •, IIP-7; $\square$, IIP-2; ०, IIP-4; $\triangle$, IIP-6; $\diamond$ IIP-8. 
four times and the adsorbed metal ion amounts were plotted $v s$. the number of repeatabilities and presented in figure 12 .

As seen in figure 12, the prepared metal ion imprinted polymers maintain their memory effect and structural toughness even when they are used several times.

\section{Conclusion}

In the present study, acrylamide and carboxylic acid monomers containing $\mathrm{M}^{2+} / \mathrm{HQ}$ complex were crosslinked with EGDMA or TMPTMA to produce IIP polymers as a result of radical addition polymerization. In addition, the $\mathrm{CP}$ polymers were produced through the same way, but without using metal ions.

The polymers were leached with $\mathrm{HNO}_{3}$ and distilled water for removing metal ions from the metal ion imprinted polymers. It was observed that no metal ion left in the IIPs after leaching.

The leached IIPs' IR spectra are very similar to the CP polymers' IR spectra. This shows that the leaching process does not damage the polymer's network structure, while the target type is removed.

According to the TG thermograms, the prepared CP and leached IIP polymers give one-step thermal decomposition reaction and the unleached IIP polymers give two-step thermal decomposition reaction.

According to the DSC thermograms, the polymers' glass transition temperatures were found between 54 and $78^{\circ} \mathrm{C} . T_{\mathrm{g}}$ values of the polymers prepared from mono-carboxylic acid monomers were found higher than those of the polymers prepared from di-carboxylic acid monomers. This is caused by plasticizing effects of $-\mathrm{COOH}$ groups in the polymers.

According to SEM images of the polymers, it is seen that IIPs cause an image change in the polymer matrix. However, CPs' SEM images and the leached IIPs' SEM images are similar to each other. Small morphological differences between them are resulted from the presence of the target ion in polymerization. A significant difference is seen between the SEMs of unleached IIPs and CPs. SEM images of the unleached IIPs show more differences when the target ion is bound uniformly. A rough and aggregated structure was observed on the surface of unleached IIPs due to which the metal ions are bound.

$2 \theta=16.5,18.6,29.2,32.8,35.5$ and 37.5 values in XRD results for pure $\mathrm{NiCl}_{2} \cdot 6 \mathrm{H}_{2} \mathrm{O}$ are characteristic diffraction peaks. These peaks are available in the unleached IIPs although they are not significant as much as those in the metal salt. However, it is seen that such peaks are lost in the leached IIPs evidencing that the leaching removes all nickel ions from the polymer. IIPs adsorb more metal ions compared to those that are non-imprinted. The IIP imprinting cavity zones were emerged after the target species are removed, which increases adsorption of the imprinted target species. According to the studies conducted at different $\mathrm{pH}$ degrees, the highest amount is adsorbed at $\mathrm{pH}=7.0$.

According to the studies conducted at different temperature degrees, temperature does not have a significant effect on the adsorbed amount.

According to Giles adsorption isotherm classification, adsorption of metal ions by the prepared IIPs is similar to L-type isotherms. Furthermore, type of the carboxylic acid monomer in the polymers does not have a significant effect on the adsorbed matter amount.

As a result of the repeated adsorption-desorption processes, it was seen that the prepared IIPs maintain their memory effect and toughness.

Thus, the MIIPs, which were synthesized in this study, are polymeric materials, whose metal ion adsorption capacity, efficiency and selectivity were improved, allowing the usage of it for several times. The most important feature, which makes these polymeric adsorbents distinguished from other adsorbents in the use of ion removing, is the fact that they are specific to the imprinted target. The synthesized polymeric materials may be proposed to be used in removing metal ions from waste water or for preconcentration of metal ions as an ideal material.

\section{Acknowledgements}

This work was supported by the Cumhuriyet University Scientific Research Unit (Project No. F-322). We thank the Cumhuriyet University Scientific Research Unit.

\section{References}

[1] Sheykhaghaei G, Sadr M H and Khanahmadzadeh S 2016 B. Mater. Sci. 39647

[2] Mukherjee R, Sharma A, Patil G, Faruqui D and Pattader P S G 2008 B. Mater. Sci. 31249

[3] Gupta K, Chakraborty G, Ghatak S, Jana P C and Meikap A K 2010 J. Appl. Polym. Sci. 1152911

[4] Zhao J, Han B, Zhang Y and Wang D 2007 Anal. Chim. Acta 60387

[5] Singh D K and Mishra S 2010 Appl. Surf. Sci. 2567632

[6] Saraji M and Yousefi H 2009 J. Hazard. Mater. 1671152

[7] Kaliyappan T, Kanan P and Raman A 2009 J. Macromol. Sci. A 36517

[8] Biju V M, Gladis J M and Rao T P 2003 Anal. Chim. Acta 478 43

[9] Romani J O, Pineiro A M, Barrera P B and Esteban A M 2008 Anal. Chim. Acta $\mathbf{6 3 0} 1$

[10] Peniche C, Argüelles Monal W, Davidenko N, Sastre R, Gallardo A and Roman J S 1999 Biomaterials 201869

[11] Tan Y, Zhang Y and Kan J 2009 Exp. Polym. Lett. 3333

[12] Ekici S, Işıkver Y and Saraydın D 2006 Polym. Bull. 57231

[13] Giles C H, MacEwan T H, Nakhwa S N and Smith D $1960 \mathrm{~J}$. Chem. Soc. 143973 